\title{
Participação, representação e representatividade no processo de tomada de decisão em Comitês de Bacia Hidrográfica: conceitos, reflexões e discussões
}

\author{
Participation, representation and representativeness \\ in the decision-making process of River Basin \\ Committees: concepts, reflections and discussions
}

Flávia Darre Barbosa ${ }^{a}$

Frederico Yuri Hanai ${ }^{b}$

Paulo Augusto Romera e Silvac

\begin{abstract}
a Doutoranda no Programa de Pós-Graduação em Ciências Ambientais, Universidade Federal de São Carlos, São Carlos, SP, Brasil End. Eletrônico: flavia_darre@yahoo.com.br

bProfessor no Departamento de Ciências Ambientais, Universidade Federal de São Carlos, São Carlos, SP, Brasil. End. Eletrônico: fredyuri@ufscar.br

'Engenheiro no Centro Tecnológico de Hidráulica e Recursos Hídricos. Departamento de Águas e Energia Elétrica de São Paulo, SP, Brasil End. Eletrônico: romera948@gmail.com
\end{abstract}

doi:10.18472/SustDeb.v7n3.2016.19761

\section{RESUMO}

O objetivo do presente ensaio conceitual é propor reflexões sobre a efetividade da participação dos representantes nos Comitês de Bacias Hidrográficas e questões relativas à representação e representatividade no processo de tomada de decisão sobre a gestão de Bacias Hidrográficas. Comitês de Bacia Hidrográfica são espaços que promovem a gestão participativa dos recursos hídricos. Nesses espaços estão representantes do poder público, da sociedade civil e de usuários de água. Contudo, infere-se que a efetividade e a qualidade da representação exercida pelos representantes estão comprometidas, em razão de diversos motivos. A pesquisa pautou-se na revisão da literatura sobre a temática e na análise de distintas configurações de participação social. Foi possível identificar que os Comitês de Bacia são espaços legítimos de participação, e que a qualidade da representação envolve fatores referentes à atuação dos representantes nesses colegiados, como: atuação cidadã, consciência individual sobre o espaço coletivo e compartilhamento de interesses.

Palavras-chave: Política Nacional de Recursos Hídricos. Comitês de Bacia Hidrográfica. Representação. Participação. 


\section{ABSTRACT}

This study reflects about (i) the effectiveness of the participation of members of river basin committees (ii) representation and representativeness in decision-making process in such committees. These committees, which involve public authorities, civil society and water users encourage participatory management of water resources. However, it is supposed that the effectiveness and the quality of the representation of committee members are compromised by several factors. The research was based on the review of the literature and on the analysis of different situations and possible configurations of social participation. It was found that committees are legitimate instruments for participation and that the quality of representation involves factors related to the performance of their members, such as citizen performance, individual awareness of collective spaces and interest sharing.

Keywords: Water resources policies. River basins committees of. Representation. Participation.

\section{INTRODUÇÃO}

Na década de 1980 o Brasil viveu um momento histórico com o fim da ditadura e início do processo de (re)democratização. A Política Pública tomou um novo caminho rumo a mudanças que viabilizaram a ampliação da participação da sociedade nas tomadas de decisão. Novos espaços de participação (organismos colegiados diversificados) foram garantidos pela Constituição de 1988.

Mesmo com tantas mudanças positivas trazidas pela Constituição de 1988, as relações de poder, econômicas setoriais e as assimetrias da herança advinda principalmente do período ditatorial, afetaram e afetam diretamente esses espaços de participação. A reflexão sobre esse ponto acaba direcionando o raciocínio para a assertiva de que a participação está intrinsecamente ligada à representação, pois nos espaços de participação, cabe aos representantes dos diversificados colegiados exercerem ampla representação das instituições que ali simbolizam.

O cuidado que deve ser tomado, portanto, nessas relações sociais, é de que essas relações de poder não se transformem em situações de dominação individuais ou coletivas. Ou ainda que não ultrapassem a motivação dos interesses compartilhados afetando a representatividade nos espaços representativos de participação.

Diante dos cuidados que devem ser tomados a fim de garantir que exista a representatividade nos espaços de participação, faz-se necessário refletir sobre algumas questões importantes: como é feita essa representação atualmente nos espaços de participação? Ela é efetiva? Os representantes escolhidos realmente representam os segmentos? Qual é o papel desse representante? Quais as relações/aspirações entre grupos de interesse representados?

Pensar na representação em espaços de decisão sociopolítica, tais como nos de saúde, educação, cultura e planejamento, considerando as três instâncias governamentais, seria motivo para uma discussão ampla, pois em cada espaço citado ocorrem desdobramentos diferenciados nos arranjos e formas de representação, que se tornam específicos por relações de pressão, mais ou menos diretas, entre o "cidadão cliente" e o "servidor na posição de prestador do serviço".

Ainda é substancialmente relevante o fato de que o conceito de participação da sociedade na vida política e social, assim como os substantivos e adjetivos que se desdobram de o verbo representar, está no curso da própria construção social e política das sociedades ao longo da história.

Então, o objetivo do presente ensaio conceitual foi contribuir com a discussão, de base reflexiva crítica, acerca das questões que envolvem participação e representação, no âmbito das Políticas de Recursos Hídricos com o foco direcionado aos Comitês de Bacia, com a consciência da impossibilidade de esgotamento do assunto. 


\section{ABORDAGEM METODOLÓGICA}

Para o desenvolvimento do estudo, foi feita a revisão de literatura. No primeiro momento foi realizado o levantamento bibliográfico de uma forma geral sobre os conceitos de participação, representação e democracia.

Posteriormente, os critérios de busca foram referências que abordam a participação na gestão de recursos hídricos no Brasil e sobre os Comitês de Bacia Hidrográfica. Para tanto, também foram consultadas as páginas institucionais do Planalto Federal e da Assembleia Legislativa do Estado de São Paulo, a fim de aprofundar a base teórica sobre a Política Nacional e Estadual de Recursos Hídricos.

A finalidade deste ensaio foi apresentar alguns estudos importantes sobre o tema, analisando e discutindo sobre questões relevantes a serem (re)pensadas, iniciando pelo contexto geral dos conceitos até chegar nas questões das Políticas [estado de São Paulo e Nacional] de Recursos Hídricos e dos Comitês de Bacia Hidrográfica.

Considerou-se neste estudo o estado de São Paulo como referencial comparativo e analítico da Política Nacional de Recursos Hídricos (PNRH), pois este foi o primeiro estado da União a estabelecer uma Política Estadual de Recursos Hídricos e propor as diretrizes para a formação dos Comitês de Bacia.

\section{DEMOCRACIA E PARTICIPAÇÃO NO BRASIL: UM BREVE APANHADO}

Primeiro, há de se considerar que a participação já fora outra, antes do período ditatorial. Muitos autores consideram a sociedade brasileira participativa, apontando diversos momentos da história do país para justificar tal afirmativa. Rocha (2008) cita alguns exemplos quando "os trabalhadores aprenderam a fazer greve, os camponeses a invadir terras, os estudantes a fazer passeatas, e assim por diante" (ROCHA, 2008, p. 132).

Mas, para Rocha (2008), durante a ditadura militar o Brasil viveu predominantemente um cotidiano de tanta violência que impediu a sociedade de mobilizar-se. Fecharam-se todos os canais de manifestação e diálogo, deixando os movimentos populares sem alternativas consideradas lícitas para a canalização de suas insatisfações e demandas ao Estado.

Admitindo o raciocínio de Fagnani (2005), se por um lado durante o período militar os movimentos populares ficavam com seu espaço cada vez mais restringido, por outro era fortalecida a elite por intermédio de novas políticas sociais que se pautavam no argumento da modernização institucional e financeira e que ampliavam a atuação dessas classes de alta renda na gestão dos territórios em marcha, na realidade, para uma modernização conservadora.

Atentando para o fato de que as políticas sociais durante a ditadura legitimaram ainda mais as ações, sobretudo das camadas de alta renda, há que se preocupar com a reforma democrática que viria a seguir. É preciso refletir sobre diante de quais relações sociais, econômicas e políticas passaram a existir, considerando que o país estaria reaprendendo a viver a democracia após longo período sem ela ou até mesmo que iria viver a democracia participativa de fato pela primeira vez.

O período da ditadura também revelou a dicotomia, ou falsa dicotomia: por um lado se fecharam os canais de participação popular, mas por outro o país vivenciou um momento de ascensão de novos movimentos populares, o qual impulsionou as mudanças de 1988, como as Comunidades Eclesiais de Base, o movimento operário do ABC, o Movimento dos Sem Terra, entre outras iniciativas que começariam a envolver a participação popular, como o Orçamento Participativo iniciado em Porto Alegre em 1989.

O fim da ditadura foi marcado por essas lutas que fortaleceram a então "Constituição Cidadã", que leva esse nome, pois incluiu em seu domínio mecanismos de participação no processo decisório federal e local (ROCHA, 2008). Tal processo foi impulsionado, entre outros fatores, por novos espaços sociais legitimados pela Constituição Federal de 1988, que discutiam o fim da coerção e o início de um novo 
padrão de controle social. "Além de dedicar todo um capítulo ao alargamento dos direitos sociais e da cidadania, a Carta Magna [de 1988] preparou o país para o convívio democrático após duas décadas de ditadura" (GENTIL; MARANGONI, 2008, p. 45).

No âmbito da Constituição de 1988, nascem os conselhos e colegiados que atuam nas mais diversas áreas de gestão pública. Nestes, novos espaços [arranjos] proporcionam a representação dos diversos segmentos considerados legítimos da sociedade e assim indicados pelo legislador. Os representantes falam [representam] em nome de um segmento ou organização, e não precisam necessariamente ser escolhidos por meio de eleições, como acontece com os representantes políticos tradicionais (DOWBER et al., 2008).

Conforme aponta Mendes (2007), a democracia participativa, que nessa época incorporava diretamente formas consultivas e/ou deliberativas, passou a ocorrer em diversas áreas, como saúde, educação, assistência social, criança e adolescente, cultura e meio ambiente.

Essa nova governança ampliada, mesmo que parcialmente, ao cidadão exige uma educação e atuação política que demandam valores em direção a uma democracia com maior envolvimento do cidadão, diferenciada da que vinha sendo praticada no país até a década de 1980, sob a égide da "segurança nacional" imposta pela Constituição de 1967. Nesse sentido, é necessário destacar, como parte de uma análise comportamental, que parte da geração com posição de decisão e em atividade no país, mesmo após os mais de 30 anos do fim da ditadura, ainda carrega a "herança" de atitudes e valores que dificultam a vivência coletiva em ambientes com diferenças de opinião.

Além de demandar novos valores, a elaboração da nova Constituição teve a participação direta da população, conforme afirma Ulysses Guimarães em seu discurso de 05 de outubro de 1988 em BrasíliaDF:

\begin{abstract}
“A participação foi também pela presença, pois diariamente cerca de 10 mil postulantes franquearam, livremente, as 11 entradas do enorme complexo arquitetônico do Parlamento, na procura dos gabinetes, comissões, galeria e salões. Há, portanto, representativo e oxigenado sopro de gente, de rua, de praça, de favela, de fábrica, de trabalhadores, de cozinheiros, de menores carentes, de índios, de posseiros, de empresários, de estudantes, de aposentados, de servidores civis e militares, atestando a contemporaneidade e autenticidade social do texto que ora passa a vigorar" (ULYSSES GUIMARÃES, 1988 apud REVISTA DE DIREITO, 2008, p. 596).
\end{abstract}

"Essa ênfase no papel dos cidadãos na formulação e execução de políticas é vista como um método importante para gerar legitimidade e senso de apropriação das intervenções governamentais" (EVANS et al., 2013, p. 24). Então, como sugere Evans (2013), as políticas governamentais tornam-se mais eficazes.

\title{
4 A PARTICIPAÇÃO: UMA REFLEXÃO GERAL
}

Ao refletir sobre a participação, Bordenave (1994, p. 22) discorre que "[...] a palavra participação vem da palavra "parte". Participação é fazer parte, tomar parte ou ter parte", mas ressalta que as expressões "ter", "fazer" e "tomar" adquirem sentidos diferentes dependendo da intenção do participante gerando níveis distintos de participação, que estão balizados no como se toma parte e não no quanto se faz parte (BORDENAVE, 1994).

Ainda segundo Bordenave (1994), a participação é também uma necessidade humana que vem aumentando gradativamente no Brasil e no mundo, principalmente após o advento dos meios eletrônicos de comunicação massiva que estão cada vez mais na ordem do dia, diante do descontentamento da sociedade às decisões de poucos.

Evans (2013) pondera que a participação social ou pública permite à população expressar nos espaços públicos suas necessidades e aspirações e que, dessa forma, em um processo realmente democrático, existe a prática da cidadania e que se constitui em um processo educativo.

De acordo com Romera e Silva (1978), para que o processo participativo seja contínuo, a participação 
deve ser a construção consciente de futuro que se realiza em função do presente que vive e do futuro que espera, e exige como seu princípio a formação de uma consciência crítica. Caso contrário, atende somente à necessidade imediata das pessoas em expectativas de curto prazo (a exemplo de quem espera o asfalto na rua que mora, e vai para frente da televisão assim que a sua rua é asfaltada) ou de longo prazo (de quem espera um Brasil melhor e tem trabalhado com a participação ao longo da vida, e ainda torce para o neto continuar).

Então, a priori, a participação já é dotada de valor em si mesma e deve ser compreendida como um processo de construção política-cultural-social, que passa pela esfera educacional, não sendo um fim, mas um meio em todo o processo.

Bordenave (1994, p. 12) discorre que "do ponto de vista dos setores progressistas ${ }^{1}$, a participação facilita o crescimento da consciência crítica da população, fortalece seu poder de reivindicação e a prepara para adquirir mais poder na sociedade".

O setor progressista, contudo, não é o único a compor o espaço social, além dele estão aqueles interessados em manter o status quo. Situação essa que faz da participação um conceito heterogêneo e, por isso, autores falam em níveis, dimensões, categorias, graus e escalas de participação.

Com a finalidade de auxiliar na análise da distribuição do poder de quem participa das decisões sociais e políticas, e demonstrar que existem diferentes graus de participação cidadã, Arnstei (2002) propõe uma tipologia de oito níveis de participação, a que denomina escada da participação. Os oito degraus dessa escada, conforme a autora, são: manipulação; terapia; informação; consulta; pacificação; parceria; delegações de poder e controle do cidadão.

Os dois primeiros degraus são níveis de não participação em que tomadores de decisão educam os participantes. O terceiro e quarto degraus abarcam uma concessão limitada da participação, em que a sociedade participa de parte do processo público quando informada ou consultada das decisões. 0 quinto degrau, a pacificação, é um nível superior da concessão limitada por permitir que participantes aconselhem sobre a gestão pública. Os três últimos degraus podem ser considerados como o nível alto de participação, pois a sociedade já possui grande poder de decisão nas questões públicas, abarcando o nível máximo do controle do cidadão, que pode chegar ao completo poder gerencial (ARNSTEI, 2002).

Um pouco diferente de Arnstei (2002), Bordenave (1994) propõe outra escala de participação, que chama de graus de participação considerando a relação de controle entre os participantes, que ocorre entre os membros e dirigentes presentes no espaço participativo, seja da relação entre sociedade e Estado, ou dentro dos próprios espaços [espaço público; sociedade-sociedade; espaços privados].

Para o autor, o menor grau de participação é a informação de decisões já tomadas. Em seguida está a consulta facultativa seguida de consulta obrigatória. O próximo grau seria a elaboração e recomendação de medidas. Em grau superior está a cogestão, com mecanismos de codecisão e colegialidade. Em seguida, está a delegação e o último grau é a autogestão.

Quando é priorizada a consciência crítica e a autonomia das pessoas participantes, a discussão que deve ser tratada diz respeito à qualidade e à efetividade dessa participação. Conforme Avritzer (2011), esses temas têm despertado crescentemente a atenção dos estudiosos da área de participação por dois motivos: a crescente associação entre participação e políticas públicas, bastante específicas do caso brasileiro; e a existência da preocupação de caráter mais teórico em relação ao tema da deliberação (AVRITZER, 2011) nos espaços de participação.

Diante do que foi colocado, o conceito de participação, associado à formação e ao aumento de consciência crítica sobre o processo social e histórico, precede e orienta o conceito de representação e representatividade. É possível, portanto, cogitar que a efetividade da participação está diretamente relacionada com a forma de representação e com a representatividade nos espaços, uma vez que a participação direta de todos os envolvidos muitas vezes é operacionalmente inviável. 


\section{REPRESENTAÇÃO E REPRESENTATIVIDADE NOS ESPAÇOS DE PARTICIPAÇÃO POLÍTICA}

A abordagem deste tópico é resultado de uma longa trajetória histórica de processos sociais e políticos complexos, que Pitkin (2006) retrata de forma brilhante em seu texto "Representação: palavras, instituições e ideias". Em determinada parte do texto, a autora discorre sobre quando o termo "representare", do latim, ganha a conotação política nos parlamentos do século XVII.

Além da ampla discussão e da complexidade histórica e etimológica que envolve o conceito de representação, Pitkin (2006) sugere que a representação é fenômeno cultural e político, ou seja, um fenômeno humano que significa em linhas gerais tornar presente o que está ausente.

Seguindo outra linha de raciocínio, porém chegando a considerações não tão distintas das feitas por Pitkin (2006), Dowber et al. (2008) nos ensina que representar é "fazer as vezes do outro" ou "estar no lugar do outro" em um determinado momento ou espaço. A rápida leitura da colocação de Dowber causa a impressão de que os significados sugeridos possuem a mesma função. É preciso atentar para o fato de que é possível que o primeiro significado provoque uma ação social diferente do segundo.

Pitkin (2006) e Dowber et al. (2008) fazem análises diferentes, mas consideram que a representação é uma atividade essencialmente humana e, por isso, não é linear e muito menos previsível. Assim, é preciso refletir de antemão que estar no lugar de alguém nem sempre é o agir por este alguém e que nem sempre quem não está presente estará representado, em determinado lugar ou situação.

O caso mais comum de representação referente às estruturas da política formal está associado ao sistema político eleitoral. Na democracia representativa é por meio do voto que o representante é eleito pelo povo para representá-lo, sendo então um espaço de representação bem delimitado.

No sistema político eleitoral da democracia representativa reside a ideia de uma somatória de representações pessoais, já que cada eleitor escolhe individualmente seu representante por intermédio do voto, o que leva ao risco do distanciamento entre eleitores e eleito, dependendo de como for a prática após a eleição. Conforme discorre Lüchmann (2007, p. 144), "a responsabilidade do processo decisório fica restrita aos representantes escolhidos pelo sufrágio eleitoral".

Contudo, esse estudo tratará de outro tipo de representação feita em novos espaços, não os políticos formais, mas aqueles criados a partir da Constituição Federal de 1988 no Brasil e que se organizam de forma diferente dos espaços tradicionais, ao menos teoricamente. Conforme sugerem Dowber et al. (2008), esses espaços podem ser institucionalizados, como os Conselhos de Políticas Públicas, ou menos formais, que são as mesas de negociação entre poder público e sociedade.

Em tais espaços existem os

representantes que falam em nome de um segmento ou organização, tais como conselheiros [e participantes de comitês] de políticas públicas que representam usuários ou movimentos populares, e também representantes necessários em momentos de negociação menos formais (DOWBOR et al., 2008 p. 12).

Em todos eles, o fato principal é que eleito ou escolhido o representante, este deverá representar aquele determinado grupo pelo qual se dispôs fazer a representação e que dele faz parte, no âmbito das relações coletivas e individuais. Será exercida a representação dos interesses do grupo, ou seja, atuará enquanto grupo inserido nas relações sociais estabelecendo contratos sociais e com interesses específicos do próprio grupo.

A representação, portanto, passa a ser uma relação de confiança, autonomia, controle, prestação de contas entre quem está representando e quem está sendo representado, embasadas por forças e vontades políticas como mencionam Dowber et al. (2008).

As autoras apontam também para um importante movimento entre os representantes e representados em tais situações. Consideram que tanto representantes quanto representados possuem responsabilidades, como fornecer informações e cobrar atuação [responsabilidade do representado], e buscar informações e prestar contas [responsabilidade do representante]. 
Contudo, os espaços de representação não são formados apenas por um segmento ou um único grupo defendendo seus interesses específicos. Dessa forma, é imprescindível que os representantes saibam reconhecer a necessidade de cada grupo para articular todos os interesses, buscando minimizar conflitos rumo à utopia do consenso.

Além disso, devem ser levados em conta outros desdobramentos. Cada grupo que será representado possui demandas e obrigações que devem ser (re)conhecidas, consideradas e aplicadas por todos os representantes para que estes exerçam uma representação qualificada positivamente e legítima. Assim, ali estará ocorrendo a representatividade.

A prestação de contas e os mecanismos de autorização entre representantes e representados darão a legitimidade aos representantes. (ABERS; KECK, 2008). Ainda assim, é preciso levar em conta os contextos indiretos de todos os representados para que as discussões sejam verdadeiras. Todavia, ainda haverá o risco de que os grupos não tenham a devida representatividade, uma vez que dependem de uma única pessoa para falar em nome de todos, principalmente nos momentos de deliberações.

Interpretando um texto de Lüchmann (2007) é possível constatar que a representatividade está diretamente relacionada à legitimidade de representação dos segmentos que compõem os espaços participativos, considerando as diferenças nas formas e mecanismos de escolha desses representantes em cada espaço, quantidade de assentos, grau de competência e qualificação. Além disso, a autora também atenta para o fato de que a representatividade esbarra em mecanismos de autorização, prestação de contas, responsividade e sanção. Quanto mais instaurados tais mecanismos, em teoria, maior a representatividade.

Além das questões apresentadas, Abers e Keck (2008) apontam para outras, das quais duas foram destacadas e consideradas mais pertinentes à discussão no presente ensaio. A primeira refere-se especificamente à real representação dos entes do Estado que compõem os espaços de participação, especialmente os Conselhos [e Comitês de Bacia Hidrográfica], pois para as autoras não está claro quem realmente está sendo representado pelo Estado.

A segunda está relacionada aos indivíduos representantes da sociedade civil, que compõem os espaços de representação e em sua maioria possuem nível de escolaridade médio e ou superior e renda igual ou superior a 5 salários mínimos. Tal perfil demonstra que esses indivíduos não fazem parte das classes populares, mesmo que representem a sociedade civil.

Mas a participação política, que ocorre por meio da sociedade civil organizada, deve ser considerada uma inovação para a gestão pública, e entre os espaços em que estão representantes desse segmento estão os Comitês de Bacias Hidrográficas.

\section{COMITÊS DE BACIA HIDROGRÁFICA: ESPAÇOS DE PARTICIPAÇÃO E REPRESENTAÇÃO}

Após a promulgação da Constituição de 1988, o estado de São Paulo foi o primeiro a estabelecer, em sua Constituição Estadual de 1989, as diretrizes da gestão dos recursos hídricos para o estado por meio da seção II do Capítulo IV. Destaca-se a ampliação da participação que essa legislação proporcionou ao congregar município, órgãos estaduais e sociedade civil no gerenciamento dos recursos hídricos.

É preciso ressaltar que a Constituição de 1988 também trouxe novidades relacionadas à gestão de recursos hídricos no país, quando definiu o princípio de que os cursos de água do território nacional passariam a bens de domínio público extinguindo o domínio privado da água. Além disso, estabeleceuse a criação, no artigo 21, inciso XIX, de instrumentos a fim de contribuir para a gestão como o Sistema Nacional de Gerenciamento de Recursos Hídricos e critérios de outorga de direitos e de uso da água (BRASIL, 1988). 
Tais mudanças permitiram que em 1991 fosse criada a primeira Política Estadual de Recursos Hídricos do país, com a Lei Estadual n. 7.633 (São Paulo), que apresenta uma nova proposta na forma de gerenciamento desses recursos, pois integra as formas de uso à qualidade e quantidade das águas, e a gestão passa a ser descentralizada e participativa (JACOBI; FRACALANZA, 2005). Para Martins (2015, p. 221), "no Brasil, o movimento que se tem nomeado por governança da água passa justamente pelos processos de descentralização administrativa e pela participação de distintos setores sociais nas práticas gestoras".

É sob esses princípios, somados aos da Constituição de 1988, que é instituído o Sistema de Gerenciamento de Recursos Hídricos no estado de São Paulo, com a abertura para a criação de colegiados representativos, deliberativos e consultivos, os Comitês de Bacia Hidrográfica, até então inexistentes no país conforme essa atribuição legal de poder de Estado institucionalizada por uma lei estadual (BRASIL, 2011).

Abers e Keck (2004) destacam que Comitês de Bacia - além do dever de serem amplamente representativos, uma vez que podem participar do processo decisório -, a sociedade civil e os representantes do poder público, também são peças centrais da reforma sobre a política da água no país.

Sobre a composição dos Comitês de Bacia no estado de São Paulo, o Artigo 24 - incisos I, II e III da Lei n. 7.633 - determina que estes, deverão:

assegurada a participação paritária dos Municípios em relação ao Estado ser compostos por: I - representantes da Secretaria de Estado ou de órgãos e entidades da administração direta e indireta, cujas atividades se relacionem com o gerenciamento ou uso de recursos hídricos, proteção ao meio ambiente, planejamento estratégico e gestão financeira do Estado, com atuação na bacia hidrográfica correspondente; II - representantes dos municípios contidos na bacia hidrográfica correspondente; III - representantes de entidades da sociedade civil, sediadas na bacia hidrográfica, respeitado o limite máximo de um terço do número total de votos, por: a) universidades, institutos de ensino superior e entidades de pesquisa e desenvolvimento tecnológico; b) usuários das águas, representados por entidades associativas; c) associações especializadas em recursos hídricos, entidades de classe e associações comunitárias, e outras associações não governamentais (SÃO PAULO, 1991).

É muito importante notar que na Lei n. 7.633 do estado de São Paulo os grandes usuários de água, universidades e as associações comunitárias estão em um único segmento representativo dentro dos Comitês, que é o da sociedade civil organizada. Ademais, estão os segmentos do poder público dos representantes do Estado e dos municípios.

A lei estadual paulista pode ser considerada inovadora, já que, historicamente, a gestão de águas no Brasil se desenvolveu de forma fragmentada em função dos setores econômicos realizarem o seu próprio planejamento, e centralizada nos governos estaduais e federal, uma vez que estes definiam as políticas sem a participação dos governos municipais, dos usuários da água e da sociedade civil (ABERS; KECK, 2004).

Embora haja a paridade na composição dos Comitês paulistas, o poder público possui maior quantidade de votos em relação à sociedade civil organizada, que deve dividir seus votos em três grupos, o que por um lado incentiva a articulação desses grupos, mas, por outro, pode enfraquecer ainda mais a participação dos grupos que possuem menor mobilização.

Após a articulação de várias outras Unidades da Federação, que se somaram à iniciativa ocorrida no estado de São Paulo, foi instituída em 1997 a PNRH (BRASIL, 1997). Esta adotou modelo semelhante ao propor a gestão descentralizada e participativa, integrando ao Sistema Nacional de Gerenciamento de Recursos Hídricos, entre outras, a instância participativa dos Comitês de Bacia Hidrográfica.

Diferente da legislação do estado de São Paulo, a PNRH dispõe que os Comitês de Bacia deverão ser formados, conforme Artigo 39, por representantes: 


\begin{abstract}
I - da União; II - dos Estados e do Distrito Federal cujos territórios se situem, ainda que parcialmente, em suas respectivas áreas de atuação; III - dos Municípios situados, no todo ou em parte, em sua área de atuação; IV - dos usuários das águas de sua área de atuação; $V$ - das entidades civis de recursos hídricos com atuação comprovada na bacia. Incluindo ainda um representante do Ministério das Relações Exteriores para rios fronteiriços e transfronteiriços de gestão compartilhada, e representantes de Comunidades Indígenas e da Funai em bacias que abrangem terras indígenas (BRASIL, 1997).
\end{abstract}

A PNRH não condiciona a legislação de recursos hídricos do estado de São Paulo a alterar a configuração dos Comitês de Bacia, porém, alguns estados brasileiros que tiveram suas legislações de recursos hídricos criadas a partir de 1997, já consideraram a formação para os Comitês proposta na PNRH, como é o caso do estado de Minas Gerais, Acre, Bahia, entre outros.

Ao adotar essa outra configuração para a participação (e representação) nos Comitês de Bacia, que coloca os usuários de água em um segmento separado da sociedade civil organizada, a PNRH:

propõe uma política participativa e um processo decisório aberto aos diferentes atores sociais vinculados ao uso da água, dentro de um contexto mais abrangente de revisão das atribuições do Estado, do papel dos usuários e do próprio uso da água (JACOBI; FRACALANZA, 2005, p. 43).

Com relação à escolha dos representantes, o parágrafo 1 do Art. 39 da Lei n. 9.433/1997 orienta que tanto o número quanto os critérios de indicação de representantes de cada setor mencionado devem ser estabelecidos nos regimentos internos dos Comitês, e a representação dos poderes executivos da União, Estados, Distrito Federal e Municípios é limitada à metade do total de membros. Normalmente a escolha é feita entre seus pares, convocados mediante publicação de edital para escolha dos representantes (BRASIL, 2011).

Em nota, Abers e Keck mencionam que essa configuração faz dos Comitês espaços complexos de representação e que suas competências variam consideravelmente entre os estados, mas que "[...] normalmente incluem aprovar e acompanhar a execução de planos de recursos hídricos, arbitrar conflitos e estabelecer mecanismos de cobrança pelo uso da água bruta" (ABERS; KECK, 2008, p. 103).

Em 2010, Abers (2010) observou um aspecto não virtuoso dessa configuração, o qual diz que o sistema, resultado dessa construção institucional, por ser complexo e diversificado, leva a relações intensas resultantes da diversidade das organizações que o compõe, e impedindo muitas vezes a gestão eficaz da água.

Mesmo com a diferença de regulação estrutural entre a PNRH e a Política de recursos hídricos do estado de São Paulo, em que há variação do percentual de participação e divisão dos segmentos, os Comitês de Bacia devem integrar representantes do governo, dos grandes usuários de recursos hídricos e da sociedade civil organizada (MARTINS, 2015).

Assim, a composição e articulação dos segmentos no Comitê deveriam fazer desses espaços arenas políticas responsáveis pela governança da água. Regionalmente deveriam constituir-se, por conta de sua estrutura e atuação, em um efetivo parlamento das águas (MARTINS, 2015).

A Agência Nacional de Águas (ANA) explica que, "muitas vezes, é comum um representante eleito entre seus pares defender interesses próprios ou particulares, seus ou da entidade que representa diretamente, e não compartilhar com o grupo as questões debatidas" (BRASIL, 2011, p. 37). Assim, quando praticada dessa forma, a representação não possui legitimidade e qualidade, portanto, não há a representatividade e o "Parlamento das Águas" não acontece.

Martins (2015) atenta para outra situação que afeta a representatividade nesses espaços participativos: as desigualdades presentes no processo deliberativo. Para ilustrar essa situação, o autor cita uma pesquisa realizada no projeto Marca d’Água, em 2004, com 626 membros de 18 organismos de Bacia (14 Comitês de Bacia e quatro consórcios intermunicipais), de várias partes do Brasil. Conforme o autor:

para $67 \%$ desses partícipes, as diferenças de conhecimento técnico se constituiriam no principal fator de desigualdade; $51 \%$ apontaram a desigualdade de poder político e $31 \%$ a desigualdade resultante do poder econômico. Para esses partícipes, essas modalidades de desigualdade afetariam indubitavelmente a lógica representativa dos setores e grupos sociais presentes nas instâncias de governança (ABERS, 2010 apud MARTINS, 2015, p. 225.). 
Ao estabelecer esses espaços participativos, a gestão centralizada, desenvolvida até então, dá lugar a uma gestão descentralizada, muito embora esse não seja o único motivo para a descentralização. Jacobi e Fracalanza (2005) atribuem a descentralização também à adoção da Bacia Hidrográfica como unidade para planejamento e gestão.

É importante fazer a ressalva de que os municípios passam a ser considerados na gestão por conta da adoção das Bacias Hidrográficas como unidade para gestão dos recursos hídricos, sendo este um dos fundamentos da PNRH e um dos princípios da Política de recursos hídricos do estado de São Paulo, e assim os Comitês de Bacia assumem o papel central na gestão dessas unidades, já que sua área de atuação é a Bacia Hidrográfica.

A delimitação do território da Bacia Hidrográfica deverá ser realizada ponderando caso a caso, conforme contextos locais, regionais, estaduais e nacionais - levando em consideração características físicas, econômicas e culturais -, existindo, assim, delimitações de bacias de domínios Estaduais e Federais.

A atuação dos Comitês se dará conforme: a totalidade de uma Bacia Hidrográfica, a Sub-bacia Hidrográfica de tributário do curso de água principal da bacia, ou de tributário desse tributário, ou por grupo de Bacias ou Sub-bacias Hidrográficas contíguas (BRASIL, 1997).

Além das situações apontadas, outras ainda comprometem a qualidade de representação e a participação nesses espaços, mesmo passados quase 20 anos da instituição da PNRH, como:

a) nem todas as bacias estaduais ou federais possuem Comitês de Bacia instaurados ${ }^{2}$ e a própria legislação permite que sejam feitos outros arranjos para a gestão dos recursos hídricos;

b) os conhecimentos técnicos dos representantes dos órgãos públicos muitas vezes sobrepõem às falas dos representantes da sociedade civil que não possuem linguagem técnica;

c) mesmo em lugares onde o Comitê está estabelecido, dificuldades de participação, por conta de fatores logísticos e operacionais, como custos de deslocamento, impedem que todos os representantes dos colegiados estejam presentes em todas as reuniões;

d) a grande preocupação por parte dos membros do Comitê ainda está direcionada à cobrança dos recursos hídricos e, nesse caso, prevalece o discurso das corporações e dos grandes usuários de água;

e) em muitos casos, os interesses dos órgãos públicos se sobrepõem aos interesses dos outros grupos, não havendo consenso ou articulações intersetoriais e interinstitucionais.

Para este ensaio escolheu-se estudar principalmente os aspectos da formação estrutural e composição dos Comitês de Bacia, bem como seus desdobramentos, tendo em vista que são o ponto de partida para se ter a compreensão do que essa estrutura legal pode proporcionar à gestão de recursos hídricos no país. As outras situações apontadas acima, de "a" a "e", ainda precisam ser estudadas e aprofundadas.

\section{CONCLUSÃO}

É incontestável que o processo de democratização do Brasil trouxe muitos avanços para a abertura à participação e melhorias na qualidade de representação, quando diversas legislações instituíram espaços participativos, consultivos e deliberativos de políticas públicas.

Entretanto, esses espaços são ainda essencialmente representativos, mais um motivo para a consciência política ser um dos princípios do processo de participação social/pública, necessário para a construção de uma sociedade mais justa, com decisões consensuadas e dialógicas.

A herança histórica reforçada pela ditadura militar, que desconsidera a participação social e o diálogo igualitário, contribui para os discursos truncados dentro dos espaços de participação democráticos que colocam em risco a legitimidade desse tipo de representação. 
Diante deste estudo, verificou-se que a legitimidade de representação dos segmentos, ou colegiados, nos espaços de participação pode ser questionada por diversos critérios, inclusive o critério de escolha dos representantes, sendo necessárias considerações e reflexões sobre a qualidade da representação na estrutura formadora do conceito de representatividade.

Com relação à gestão dos recursos hídricos, propriamente dita, espera-se que nos espaços participativos dos Comitês de Bacia Hidrográfica esteja a representação de "toda" a sociedade, por meio da definição de representantes do poder público, usuários e organização civil de forma legítima.

Estudos e questões levantados neste ensaio apontam para o fato de que existe a participação (principalmente pela obrigatoriedade da própria legislação) e, analisando minuciosamente a legislação e a forma de escolha dos representantes, é possível dizer que com a configuração estrutural a representação estará garantida, ou seja, os Comitês de Bacia são estruturas que permitem uma participação pública menos inerte.

Por outro lado, não há como qualificar a efetividade dessa representação, ou seja, não é possível avaliar e garantir a representatividade apenas sob a óptica da legislação. É preciso questionar e viabilizar a atuação do "parlamento das águas", e mais, se a representação social está contribuindo para a efetivação dos objetivos da Política Nacional de Recursos Hídricos, esperada pela sociedade.

Além disso, o conjunto de representações nos Comitês de Bacia Hidrográfica, em geral, se traduz em interesses diferenciados dos segmentos representados. Os usuários têm seus interesses direcionados à disponibilidade e à qualidade da água, em usos concorrentes e muitas vezes conflitantes entre o próprio segmento; o poder público tem o interesse voltado em promover a implantação das políticas setoriais; a sociedade civil possui uma multiplicidade de interesses que podem ser focados tanto em aspectos coletivos como em interesses corporativos (BRASIL, 2011).

A partir das reflexões apresentadas, levantam-se outros questionamentos: até que ponto o representante realmente representa os interesses do grupo? Até que ponto esse representante sabe reconhecer os outros grupos nos espaços? As respostas para essas indagações envolvem outros aspectos, relacionados à atuação cidadã, à prática dos direitos e deveres civis, ao processo educacional e de consciência sobre o espaço coletivo. Tudo isso se reflete em uma compreensão mais ampla do sentido da Política Nacional de Recursos Hídricos, que deve considerar as multiplicidades nas relações do local com o global.

Dessa maneira, para que sejam confirmadas ou ao menos confrontadas todas as hipóteses existentes sobre a qualidade da participação e, consequentemente, da representação nos espaços deliberativos dos Comitês de Bacia, é necessário ainda que se façam outros estudos (teóricos e práticos) nesses espaços. Também é imprescindível que o processo de participação seja incorporado nas discussões e pautas desses colegiados.

É preciso que se aproxime a ciência e a linguagem técnica, da vida cotidiana dos Comitês, da percepção e da vivência dos participantes do colegiado. Com isso, um amplo processo de comunicação e de difusão tecnológica em recursos hídricos deve ser incentivado, considerando as dimensões físicas, econômicas, sociais, culturais e políticas e não somente corporativistas ou de uma economia hegemônica exploratória, que coloca os interesses de poucos à frente do bem coletivo socioambiental, aqui relacionado aos recursos hídricos, ou simplesmente à água.

Para que seja mais efetiva a participação na gestão dos recursos hídricos também deve se considerar e incentivar a participação voluntária, que ocorre em outros espaços de participação que não são necessariamente os institucionalizados.

Por fim, é possível considerar que a representatividade das instituições nos espaços de participação será efetiva se as ações sociais plurais de cada um dos representantes caminharem no sentido de interesses compartilhados, racionalmente motivados, para se tornarem relações sociais fortalecidas nas estruturas de gestão democrática e participativa dos recursos hídricos no Brasil. 


\section{NOTAS}

${ }^{1} \mathrm{O}$ autor não define o setor progressista, mas sabendo que o autor escreve no contexto da década de 1980 , provavelmente se referia aos partidos de esquerda, contra regimes totalitários e ditadores. Neste artigo assume-se a conceituação de que: o setor progressista é aquele que acredita que as mudanças são mais importantes do que manter a tradição do que existe. Então está disposto a colocar a tradição em risco.

${ }^{2}$ Conforme experiência profissional da autora*, muitos Comitês estão em processo de instalação, outros estão em processo de reconfiguração, portanto, não é possível contabilizar a quantidade exata de Comitês no Brasil até 2016. Segundo dados do Sistema Integrado de Gerenciamento de Recursos Hídricos e Comitês de Bacia, atualizados em 2015, são 197 Comitês Estaduais e nove Comitês interestaduais de domínio Federal.

*A autora trabalhou no projeto Água: conhecimento para gestão, lecionando em 13 estados brasileiros para capacitação dos membros do Sistema Nacional de Gerenciamento de Recursos Hídricos (Singrh), entre os anos de 2013 e 2015.

\section{REFERÊNCIAS}

ABERS, R. N (Org.) Água e Política: atores, instituições e poder nos organismos colegiados de bacia hidrográfica no Brasil. São Paulo: Annablume, 2010. 246 p.

; KECK, M. Comitês de Bacia no Brasil: uma abordagem política do estudo da participação social. Revista Brasileira de Estudos Urbanos e Regionais (Anpur), v. 6, n. 1, 2004. P. 55-69.

; JORGE, K. D. Descentralização da Gestão da Água: por que os comitês de bacia estão sendo criados? Revista Ambiente \& Sociedade, v. VIII, n. 2, jul./dez. 2005. Disponível em: <http://www.scielo.br/>. Acesso em: set. 2015.

KECK, M. E. Representando a diversidade: estado, sociedade e "relações fecundas" nos conselhos gestores. Dossiê. Caderno CRH, Salvador, v. 21, n. 52, 2008, p. 99-112.

ARNSTEIN, S. R. Uma escada da participação cidadã. Revista da Associação Brasileira para o Fortalecimento da Participação - Participe, Porto Alegre/Santa Cruz do Sul, v. 2, n. 2, p. 4-13, jan. 2002.

AVRITZER, L. A qualidade da democracia e a questão da efetividade da participação: mapeando o debate. In: PIRES, R. R. C. (Org.). Efetividade das instituições participativas no Brasil: estratégias de avaliação. Diálogos para o desenvolvimento. Brasília: Ipea, 2011, v. 7. p. 13-29.

BORDENAVE, J. E. D. O que é participação. São Paulo: Ed. Brasiliense, 1994.

BRASIL. Agência Nacional de Águas (ANA). O Comitê de Bacia Hidrográfica: o que é e o que faz? / Agência Nacional de Águas. Cadernos de capacitação em recursos hídricos. Brasília: SAG, 2011, v. 1., 64 p.

Presidência da República. Constituição da República Federativa do Brasil de 1988. Institui o Estado Democrático e dá outras providências. Disponível em <http://www.planalto.gov.br>. Acesso em: jun., ago., nov. 2015.

Presidência da República. Lei Federal n. 9.433, de 8 de janeiro de 1997. Institui a Política Nacional de Recursos Hídricos, cria o Sistema Nacional de Gerenciamento de Recursos Hídricos e dá outras providências. Casa Civil: Subchefia para Assuntos Jurídicos. Disponível em: <www.planalto.gov.br/ccivil_03/leis/L9433.htm>. Acesso em: 04 mai. 2015 e mar. 2016.

DOWBOR, M.; PETER, H.; LIZANDRA, S. Enfrentando os desafios da representação em espaços participativos São Paulo: CEBRAP: IDS, 2008. 48p. 
EVANS, M. et al. Participação Social: lições aprendidas na Europa. In: ANTERO, S. A.; SALGADO, V. A. B. (Org.). Participação Social: textos para discussão. Fundação Instituto para o Fortalecimento das Capacidades Institucionais - IFCI / Agência Espanhola de Cooperação Internacional para o Desenvolvimento - Aecid / Ministério do Planejamento, Orçamento e Gestão - MPOG / Editora IABS, Brasília-DF, Brasil, 2013. p. 11-105.

FAGNANI, E. Política social no Brasil (1964-2002): entre a cidadania e a caridade. Tese (Doutorado em Ciências Econômicas) - Universidade Estadual de Campinas. Unicamp. Campinas, SP. 2005.

GENTIL, D. L.; MARANGONI, G. A Constituição de 1988 e a Seguridade Social: uma disputa em meio à financeirização do Estado. In: VAZ, F. T.; MUSSE, J. S.; SANTOS, R. F. dos. 20 anos da Constituição Cidadã: avaliação e desafios da Seguridade Social. Brasília: Anfip, 2008, p. 45-54.

GUIMARÃES, U. Discurso do deputado Ulysses Guimarães, presidente da Assembleia Nacional Constituinte, em 05 de outubro de 1988, por ocasião da promulgação da Constituição Federal. Revista Direito GV, São Paulo, juldez. 2008. p. 595-602.

JACOBI, P. R.; FRACALANZA, A. P. Comitês de Bacias Hidrográficas no Brasil: desafios de fortalecimento da gestão compartilhada e participativa. Desenvolvimento e Meio Ambiente. Editora UFPR. n. 11-12, jan./dez. 2005. p. 4149.

LÜCHMANN, L. H. H. Democracia deliberativa, pobreza e participação política. Política e Sociedade. Revista de Sociologia Política. Florianópolis, SC. Brasil. Editora UFSC, v. 6, n. 11, 2007, p. 183-197.

MARTINS, R. C. Fronteiras entre desigualdade e diferença na governança das águas. Ambiente \& Sociedade. São Paulo, v. XVIII, n. 1, jan.-mar. 2015, p. 221-238. Disponível em: <http://www.scielo.br/>. Acesso em: fev. 2016.

MENDES, C. V. R. Representação política e participação: reflexões sobre o déficit democrático. Revista Katál. Florianópolis, v. 10, n. 2, jul./dez. 2007, p. 143-153.

PITKIN, H. F. Representação: palavras, instituições e ideias. Lua Nova, São Paulo, 67, 2006, p. 15-47.

ROMERA E SILVA, P. A. Plano de Ação Comunitária, Piracicaba, SP, 1978. s/ed.

ROCHA, E. A Constituição Cidadã e a institucionalização dos espaços de participação social: avanços e desafios. In: VAZ, F. T.; MUSSE, J. S.; SANTOS, R. F. dos. 20 anos da Constituição Cidadã: avaliação e desafios da Seguridade Social. Brasília: Anfip, 2008, p. 131-148.

SÃO PAULO. Assembleia Legislativa do Estado de São Paulo. Lei Estadual n. 7.663, de 30 de dezembro de 1991. Disponível em: <http://www.al.sp.gov.br/>. Acesso em: nov. 2015 e mai. 2016. 